Issued by Sandia National Laboratories, operated for the United States Department of Energy by Sandia Corporation.

NOTICE: This report was prepared as an account of work sponsored by an agency of the United States Government. Neither the United States Government, nor any agency thereof, nor any of their employees, nor any of their contractors, subcontractors, or their employees, make any warranty, express or implied, or assume any legal liability or responsibility for the accuracy, completeness, or usefulness of any information, apparatus, product, or process disclosed, or represent that its use would not infringe privately owned rights. Reference herein to any specific commercial product, process, or service by trade name, trademark, manufacturer, or otherwise, does not necessarily constitute or imply its endorsement, recommendation, or favoring by the United States Government, any agency thereof, or any of their contractors or subcontractors. The views and opinions expressed herein do not necessarily state or reflect those of the United States Government, any agency thereof, or any of their contractors.

Printed in the United States of America. This report has been reproduced directly from the best available copy.

Available to DOE and DOE contractors from

U.S. Department of Energy

Office of Scientific and Technical Information

P.O. Box 62

Oak Ridge, TN 37831

Telephone: (865)576-8401

Facsimile: (865)576-5728

E-Mail: reports@adonis.osti.gov

Online ordering: http://www.doe.gov/bridge

Available to the public from

U.S. Department of Commerce

National Technical Information Service

5285 Port Royal Rd

Springfield, VA 22161

Telephone: (800)553-6847

Facsimile: (703)605-6900

E-Mail: orders@ntis.fedworld.gov

Online order: http://www.ntis.gov/ordering.htm

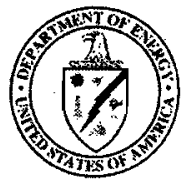


SAND2002-0083

Unlimited Release

Printed January 2002

\title{
Bending Effects in the Frictional Energy Dissipation in Lap Joints
}

\author{
Martin W. Heinstein and Daniel J. Segalman \\ Engineering Sciences Center \\ Sandia National Laboratories \\ P.O. Box 5800 \\ Albuquerque, NM 87185-0847
}

\begin{abstract}
Frictional energy dissipation in joints is an issue of long-standing interest in the effort to predict damping of built up structures. Even obtaining a qualitative understanding of how energy dissipation depends on applied loads has not yet been accomplished. Goodman[1] postulated that in harmonic loading, the energy dissipation per cycle would go as the cube of the amplitude of loading. Though experiment does support a power-law relationship, the exponent tends to be lower than Goodman predicted. Recent calculations discussed here suggest that the cause of that deviation has to do with reshaping of the contact patch over each loading period.
\end{abstract}




\section{Acknowledgments}

The authors want to thank Dr. Donald Lobitz of Sandia National Laboratories and Professor Xiaomin Deng of the University of South Carolina for sharing with us over time their evolving understanding of these problems. They have been generous with their time and their insights. 


\section{Contents}

$\begin{array}{ll}\text { Mathematical Symbols } & 6\end{array}$

$\begin{array}{ll}\text { Introduction } & 7\end{array}$

Classic Contact Analysis $\quad 8$

Investigation Via Finite Element Analysis $\quad 9$

$\begin{array}{lr}\text { Oscillatory Loading } & 10\end{array}$

Plate Kinematics $\quad 11$

$\begin{array}{lr}\text { Conclusions } & 13\end{array}$

References $\quad 13$ 


\section{Mathematical Symbols}

$L \quad$ length of slip zone

$F_{0} \quad$ amplitude of applied load

$C_{S} \quad$ coefficient relating length of slip zone and applied load

$p(x)$ normal traction at distance $\mathrm{x}$ from the edge of contact patch.

$C_{p} \quad$ coefficient relating normal traction and distance from edge of contact patch

$\alpha \quad$ exponent relating normal traction and distance from edge of contact patch

$u(x) \quad$ lateral slip at distance $\mathrm{x}$ from the edge of contact patch.

$C_{u} \quad$ coefficient relating lateral slip and distance from edge of contact patch

$\beta \quad$ exponent relating lateral slip and distance from edge of contact patch 


\section{Introduction}

There is a long history of research into frictional energy dissipation in built up structures. Some early work focussed on predicting the vibration damping to be expected in aircraft due to frictional damping around rivets[2], but the evolving interests seem to include frictional vibration damping in jet engine components and the mitigation of shock spectra seen in the transport of critical components. (Two broad discussions on the application to jet engines can be found in [3] and [4] and a historically interesting article can be found in [5].)

Early work in trying to understand this process and its role in mitigating fatigue in aircraft structures lead Ungar [6] to perform experiments studying the energy dissipation per cycle in lap joints subject to harmonic lateral loads. Ungar found that at low and moderate force amplitudes, the energy dissipation seemed to grow as force amplitude to a fractional power. He demonstrated how the value of that exponent could be used to deduce the nature and source of the dissipative process.

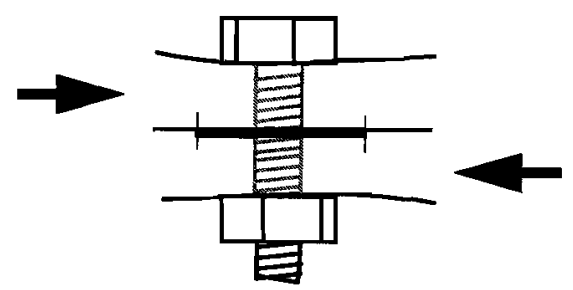

Figure 1. Ungar pioneered the use of energy dissipation per cycle as a function of lateral force amplitude to identify dissipative mechanisms.

About ten years previously, Goodman [1] postulated that for a large class of contact problems involving harmonic lateral loads, the energy dissipation should go as force amplitude to the third power. Goodman illustrated his postulate relationship by scrutinizing the predictions of Mindlin contact results[7,8].

Consistent with Goodman's predictions, Ungar's later experiments and all succeeding research seem to support a power-law relationship between amplitude of applied load and dissipation rate, but in each case, the exponent seems to lie substantially below 3.0. This deviation of experiment from analytical prediction has often been ascribed to either mechanical losses taking place just below the surfaces or to inadequacies in the constitutive equations for friction used in achieving the analytic results[9].

This monograph will demonstrate that the sub-cubic exponents found experimentally may be due to complicated contact kinematics that have not been considered in analytic solutions. 


\section{Classic Contact Analysis}

The classical analyses pioneered by Galin[10] and extended by Mindlin $[7,8]$ and others all seem to have in common either very stiff boundary conditions or geometric and loading symmetry that guarantee that the location and extent of the contact patch will not change appreciably during the loading cycle. These conditions also guarantee that the slip regions on push and pull should be mirror images.

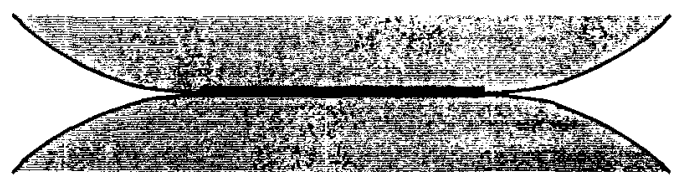

Figure 2. The classical contact analyses postulate boundary and loading conditions that assure that the contact patch does not change position or extent during lateral loading, though the outer regions of the contact patch do slip.

These conditions are very constraining and it will be shown below that they do not seem to apply on more reasonable geometries. First, it would seem worthwhile to discuss the kind of contact mechanics that Goodman appeared to have in mind. In particular, each of the examples used to illustrate Goodman's postulate $[1,11]$ involve slip zones at the edges of the contact patches for which the length, $L$, of the slip zone increases linearly with the force:

$$
L=C_{S} F_{0}
$$

the normal load varies over that contact patch as

$$
p(x)=C_{p} x^{\alpha},
$$

and the lateral displacement goes as

$$
u(x)=\dot{C_{u}}(L-x)^{\beta}
$$

Above,

$x \quad$ is distance from the edge of the contact patch;

$F_{0} \quad$ is the amplitude of applied load;

$C_{S} \quad$ is a coefficient relating length of slip zone and applied load;

$C_{p} \quad$ is a coefficient relating normal traction and distance from edge of contact patch;

$\alpha \quad$ is an exponent relating normal traction and distance from edge of contact patch;

$C_{u} \quad$ is a coefficient relating lateral slip and distance from front of the slip zone; 
$\beta \quad$ is an exponent relating lateral slip and distance from front of the slip zone.

In each of the cases examined, the exponents $\alpha$ and $\beta$ sum to 2 and the dissipation integrates exactly to 3.0. It is important to note that in these analysis, though the inner edge of the slip zone moves toward the center of the contact patch as load is increased, the contact patch does not change and the outer edge of the slip zone does not move.

One might naturally begin the investigation as to why the Goodman postulate fails to match experiment with a careful scrutiny of the physics of the problem and notions of some other relationship between $\alpha$ and $\beta$. In fact this investigation might begin with a careful re-examination of the friction law employed. As natural as the above approach may appear, we argue that the more productive approach is to question the basic assumptions employed in the classical analysis.

\section{Investigation Via Finite Element Analysis}

Given the advantages of finite element tools and high performance scientific computers (such as the DEC 8400 used in these studies), it is natural to simulate numerically the full elastic contact problem to re-examine the kinematics of the contact problem. The finite element code employed in these simulations was JAS3D, developed at Sandia National Laboratories designed to solve large quasi-static nonlinear mechanics problems.

We consider a simple lap joint consisting of two plates squeezed together by a uniform normal traction in a plane strain analysis. Each plate has length 1.8 inches and thickness 0.125 inches. The two plates overlap by 0.6 inches so that the total extension is 3.0 inches. There is a $10,000 \mathrm{lb}$./in compressive load $p$ uniformly distributed over the center 0.1 inch of the overlap region. The Young's modulus is $10^{6} \mathrm{psi}$; the Poisson ratio is 0.3 ; and the coefficient of friction is 0.7 .

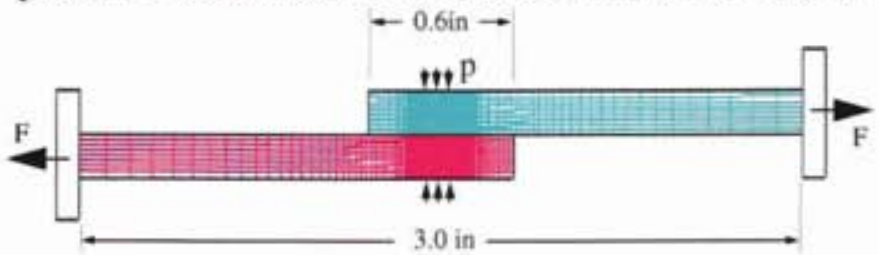

Figure 3. A finite element mesh with very fine mesh in contact patch and especially fine mesh in the slip region was employed to examine the kinematics resulting from oscillatory lateral loads. The vertical and horizontal dimensions of this figure are not to scale.

An extremely fine mesh is employed. It is very fine in the vicinity of the contact patch and especially fine over the region in which slip occurs. A typical element length over the slip zone is 0.002 inches. 


\section{Oscillatory Loading}

Oscillatory loads of $0.058 \mathrm{lb}$./in., $0.0865 \mathrm{lb}$./in., $0.116 \mathrm{lb}$./in., $0.1725 \mathrm{lb}$./in., and $0.230 \mathrm{lb}$./ in. were applied along the external edges of the two plates. In each case, the loads were applied over numerous cycles (usually 12 cycles) until the displacement fields in each cycle overlay the calculations for the previous cycle. Calculations for the accumulated frictional energy dissipation are made at the end of each load step, and 800 load steps are taken over each loading cycle. The accumulated dissipation at the end of each cycle for the last 10

Table 1: Dissipation/cycle vs. Force Amplitude

\begin{tabular}{|l|l|}
\hline Force [lb./in] & $\begin{array}{l}\text { Dissipation [lb. in/cycle] } \\
\text { (correlation coefficient) }\end{array}$ \\
\hline \hline 0.058 & $4.43 \mathrm{E}-7(0.9999499)$ \\
\hline 0.0865 & $1.61 \mathrm{E}-6(0.9999663)$ \\
\hline 0.116 & $3.65 \mathrm{E}-6(0.9999975)$ \\
\hline 0.1725 & $1.06 \mathrm{E}-5(0.9999994)$ \\
\hline 0.230 & $2.22 \mathrm{E}-5(0.9999999)$ \\
\hline
\end{tabular}

cycles was plotted against cycle number to determine the dissipation per cycle (the slope of this curve along with the correlation coefficient for the linear fit is shown in Table 1).

The energy dissipation per cycle is plotted against the corresponding loading amplitude in following figure:

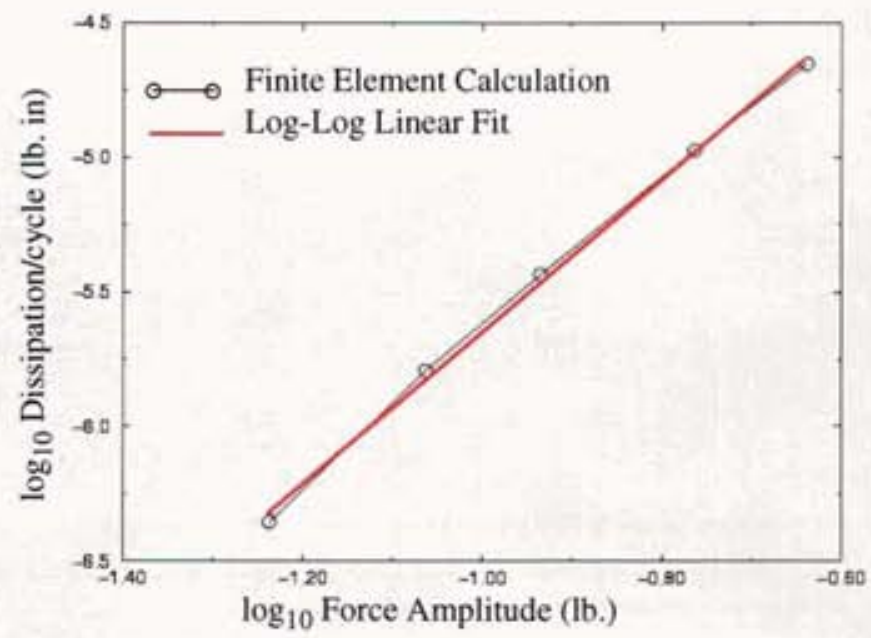

Figure 4. Calculated dissipation per cycle versus force amplitude shows a nearly linear relationship on a log-log plot.

The calculated dissipation per cycle does seem to satisfy a power-law relation. A leastsquares fit on the log-log scale yields a slope of 2.82 with a correlation coefficient of 0.99881 . If the point corresponding to the lowest load amplitude is neglected, then the slope 
through the remaining 4 points would be 2.68 with a correlation coefficient of 0.99988 . We offer this last observation only to recognize that the load amplitude of just $0.058 \mathrm{lb}$./in is quite small. At that load the finite element results for the frictional energy dissipation calculation involve only a few nodes on either side of the contact region and hence may not accurately capture the dissipation. Future numerical investigations employing mesh refinement will addess this issue.

\section{$\underline{\text { Plate Kinematics }}$}

Clearly the log-log slope presented above is inconsistent with Goodman's expectation. Why the conditions presumed by Goodman do not seem to apply here are indicated by the Figure 5, showing the energy dissipation per unit area per cycle for the intermediate case $(0.116 \mathrm{lb}$./in peak lateral load) over the length of the overlap region.

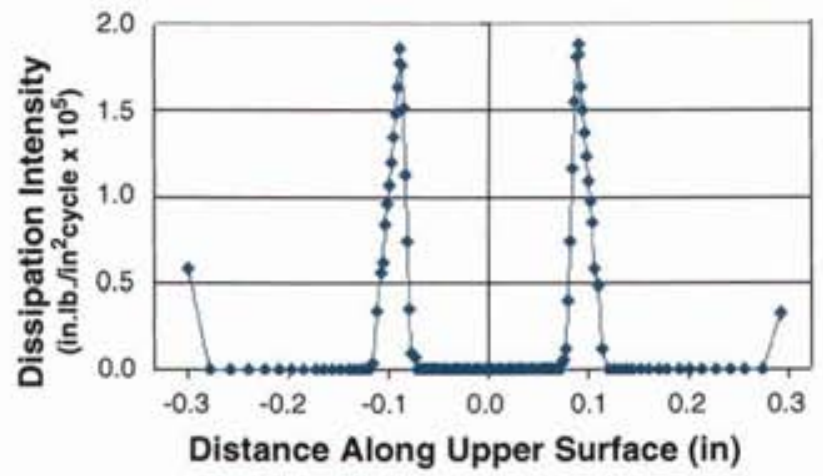

Figure 5. The energy dissipation per unit area per cycle along the upper plate shows that most of the dissipation takes place in micro-slip regions located approximately under the edges of the load pressing the plates together. There is also dissipation in the location where the end of each plate contacts the other plate during the "push" part of the cycle.

This figure demonstrates to us that there is dissipation at more than just the anticipated slip zone in the contact patch; the tip of each plate is rubbing against the length of the other plate. Though the coarseness of the mesh near the edges of the overlap region does not yield much resolution on the dissipation at the edges, still the calculations are sufficient to demonstrate that the kinematics assumed in the classical analyses do not apply.

Perhaps more important than the startling locations at which slip occurs is the cause. As the joint undergoes the compressive part of the loading cycle, the plates tend to curve towards each other. In the tensile part of the loading cycle, the plates bend away from each other. These results of the finite element analysis are consistent with a "strength of materials" understanding of how the 
elastic system would respond to the static loads. These kinematics are illustrated in an exaggerated manner in Figure 6.

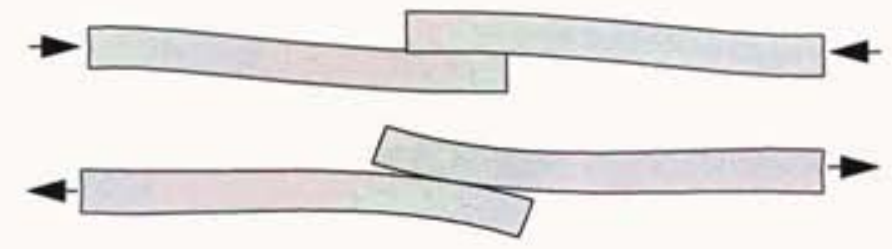

Figure 6. Consideration of the static loads and the naturally resulting deformations of the plates explains the finite element results showing opposite curvatures resulting in tension and compression.

We see below that the tensile part of the cycle yields its own surprises.

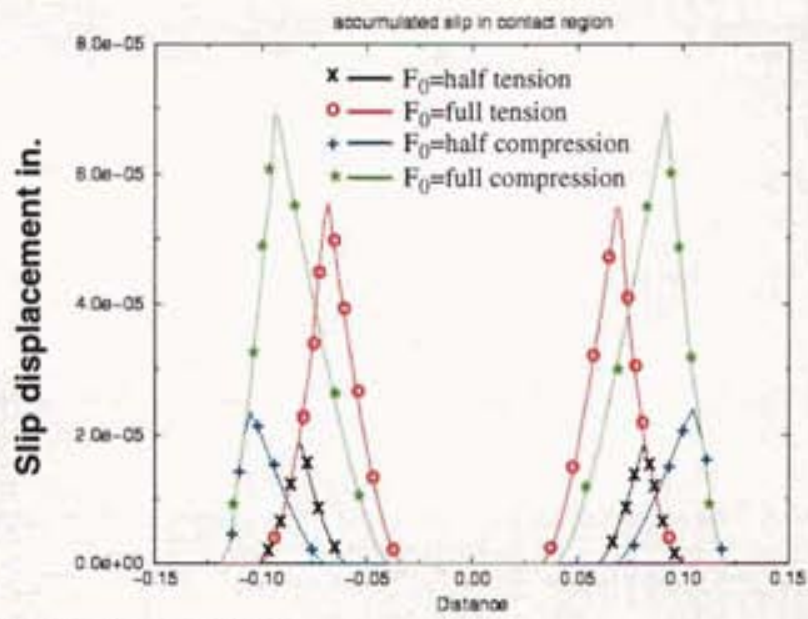

Figure 7. The accumulated slip in the instantaneous slip zone for half way and at the peak of the full compression portion of th cycle. Also shown are the corresponding curves for the tension part of the cycle. (Symbols on curves are for identification only and do not correspond to specific nodes.)

Figure 7 shows the accumulated slip on each of the slip zones for two levels of tension and two levels of compression. As expected by the classical theory, in the compression part of the cycle, the slip zone has its outer edge at the extreme portion of the initial contact patch and the inner edge grows toward the center of the contact patch as the load increases.

Contrary to the classical analysis, in the tensile portion of the cycle, the contact patch shrinks as the plates bend away from each other. This is seen in the figure as both the inner and outer edges of the slip zone move toward the center of the contact patch. 


\section{Conclusions}

The calculations presented here argue the following two important points:

the kinematics assumed in the classical contact analysis is suspect and may be the cause for deviation between experiment and the classical predictions of energy dissipation.

analysis that accounts for more global deformations resulting from the applied loads must be considered in predicting the dissipative nature of joints.

Finally, it must be conceded that the above calculations are themselves very crude. More calculations must be done to verify the results. In particular, these finite element tools must be employed in problems like the idealized ones imagined by Goodman to assure that they are capable of reproducing the classical results. This will be part of a systematic research effort at Sandia National Laboratories

\section{References}

1. Goodman, L.E., 1959, "A Review of Progress in Analysis of Interfacial Slip Damping”, in Proceedings of the ASME Colloquium on Structural Damping, edited by Jerome E. Ruzicka, ASME, New York, pp. 35-48.

2. Ungar, E.E., 1973, “The status of engineering knowledge concerning the damping of built-up structures", Journal of Sound and Vibration, 26, pp 141-154

3. Griffin J.H., 1990, "A Review of Friction Damping of Turbine Blade Vibration," International J. of Turbo and Jet Engines, Vol. 7, pp. 297-307

4. Csaba, G., 1998, Modelling Microslip Friction Damping and its Influence on Turbine Blade Vibrations, Thesis, Linköping University, Linköping , Sweden

5. Goodman, L.E. and J. H. Klumpp, 1956, “Analysis of Slip Damping with Reference to Turbine-Blade Vibration”, Journal of Applied Mechanics, September, pp. 421-429.

6. Ungar, Eric E., 1964, "Energy dissipation at structural joints; mechanisms and magnitudes", Technical Documentary Report No. FDL-TDR-64-98, Air Force Flight Dynamics Laboratory, Wright-Patterson Air Force Base, Ohio

7. Mindlin, R.D., W.P. Mason, J.F. Osmer, and H. Deresiewicz, 1952, "Effects of an Oscillating Tangential Force on the Contact Surfaces of Elastic Spheres", Proceedings of 1st National Congress on Applied Mechanics, ASME, New York, p 203,

8. Mindlin, R.D., 1949, "Compliance of Elastic Bodies in Contact”, Journal of Applied Mechanics, 16, pp. 259-268.

9. Johnson, K.L., 1985, Contact Mechanics, Cambridge University Press, New York, p 231. 
10. L. Galin,1953; "Contact Problems in the Theory of Elasticity," GITTL, Moscow, English translation: H. Moss, North Carolina State College, Raleigh, NC, 1961.

11. Segalman, D. J., 1999, “Observations on Simulation of Joint Friction”, Proceedings of the 1999 ASME Design Engineering Technical Conferences, September 12-15, Las Vegas, Nevada. 


\section{Distribution}

1 Prof. Lawrence Bergman

Univ. of Illinois

Aero/Astro Engr.

Urbana, IL 61801

1 Prof. Alexander F. Vakakis

Department of Mechanical \& Industrial Engineering

104 Mechanical Engineering Building, MC-244

1206 West Green Street

Urbana, IL 61801

1 Prof. Xiaomin Deng

Department of Mech. Engr.

University of South Carolina

Columbia, SC 29208

1 Prof. Lee Peterson

University of Colorado at Boulder

Campus Box 429

Boulder, CO 80309-0429
1 Dr. Marie Levine

Jet Propulsion Laboratory (JPL)

Science and Technology

Development Section

4800 Oak Grove Drive

Pasadena, CA 91 109-8099

1 Prof. Edward J. Berger

Dept. Mech. \& Industrial Engr.

University of Cincinnati

PO Box 210072

Cincinnati, OH 45221-0072

1 Professor Jerry Griffin

Department of Mech. Engineering

Carnegie Mellon University

Pittsburgh, PA 15213

1 Dr. Charles Cross

AFRL/PRTE

1950 Fifth St., Bldg. 18D

WPAFB, OH 45433-7251

1 Prof. Tod A. Laursen

27 Hudson Hall, Box 90287

Duke University,

Durham, NC 27708

$\begin{array}{llll}1 & \text { MS 0841 } & \text { Bickel, Thomas C } & 9100 \\ 1 & \text { MS 0824 } & \text { Ratzel, Arthur C } & 9110 \\ 1 & \text { MS 0847 } & \text { Morgan, Harold S } & 9120 \\ 1 & \text { MS 0824 } & \text { Moya, Jaime } & 9130 \\ 1 & \text { MS 0827 } & \text { McGlaun, J Michael } & 9140 \\ 1 & \text { MS 1080 } & \text { Dohner, Jeffrey } & 1769 \\ 1 & \text { MS 9042 } & \text { Dawson, Dan } & 8725 \\ 1 & \text { MS 9042 } & \text { Antoun, Bonnie } & 8725 \\ 1 & \text { MS 0893 } & \text { Brannon, Rebecca M } & 9123 \\ 1 & \text { MS 08MS } & \text { Chambers, Robert S } & 9123 \\ 1 & \text { MS 0893 } & \text { Hammerand, Daniel C } & 9123 \\ 1 & \text { MS 0893 } & \text { Lo, Chi } & 9123 \\ 1 & \text { MS 0893 } & \text { Neilsen, Michael K } & 9123 \\ 1 & \text { MS 0893 } & \text { Reedy, Dave } & 9123 \\ 1 & \text { MS 0893 } & \text { Scherzinger, William M } & 9123 \\ 1 & \text { MS 0893 } & \text { Wellman, Gerald W } & 9123 \\ 1 & \text { MS 0847 } & \text { Alvin, Kenneth F } & 9124 \\ 1 & \text { MS 0557 } & \text { Carne, Thomas G } & 9124 \\ 1 & \text { MS } 0847 & \text { Driessen, Brian } & 9124\end{array}$




\begin{tabular}{|c|c|c|c|}
\hline 1 & MS 0847 & Field, Richard V & 9124 \\
\hline 1 & MS 0191 & Ozdoganlar, O Burak & 9124 \\
\hline 1 & MS 0847 & Redmond, James M & 9124 \\
\hline 10 & MS 0847 & Segalman, Daniel J & 9124 \\
\hline 1 & MS 0557 & Simmermacher, Todd W & 9124 \\
\hline 1 & MS 0553 & Smallwood, David O & 9124 \\
\hline 1 & MS 0847 & Wojtkiewicz, Steven F Jr & 9124 \\
\hline 1 & MS 0847 & Adams, Charles R & 9125 \\
\hline 1 & MS 0557 & Baca, Thomas J & 9125 \\
\hline 1 & MS 0557 & Cap, Jerome S & 9125 \\
\hline 1 & MS 0557 & Clauss, David B & 9125 \\
\hline 1 & MS 0557 & Dorrell, Larry $\mathbf{R}$ & 9125 \\
\hline 1 & MS 0557 & Freymiller, James Eban & 9125 \\
\hline 1 & MS 0847 & Fulcher, Clay W G & 9125 \\
\hline 1 & MS 0847 & Hopkins, Ronald N & 9125 \\
\hline 1 & MS 0557 & Klenke, Scott E & 9125 \\
\hline 1 & MS 0557 & Larkin, Paul A & 9125 \\
\hline 1 & MS 0557 & Mayes, Randall L & 9125 \\
\hline 1 & MS 0557 & O'Gorman, Christian C & 9125 \\
\hline 1 & MS 0847 & Walther, Howard P & 9125 \\
\hline 1 & MS 0847 & Arguello Jr, Jose G & 9126 \\
\hline 1 & MS 0553 & Bateman, Vesta I & 9126 \\
\hline 1 & MS 0847 & Burchett, Steven N & 9126 \\
\hline 1 & MS 0847 & Duong, Henry & 9126 \\
\hline 1 & MS 0847 & Gwinn, Kenneth W & 9126 \\
\hline 1 & MS 0847 & Hinnerichs, Terry & 9126 \\
\hline 1 & MS 0847 & Holland, John F & 9126 \\
\hline 1 & MS 0847 & Jung, Joseph & 9126 \\
\hline 1 & MS 0847 & Longcope, Donald B & 9126 \\
\hline 1 & MS 0847 & May, Rodney A & 9126 \\
\hline 1 & MS 0847 & Metzinger, Kurt E & 9126 \\
\hline 1 & MS 0847 & Pott, John & 9126 \\
\hline 1 & MS 0557 & Paez, Thomas L. & 9133 \\
\hline 1 & MS 9018 & Central Technical Files, & $8945-1$ \\
\hline 2 & MS 0899 & Technical Library, & 9616 \\
\hline 1 & MS 0612 & \multicolumn{2}{|c|}{$\begin{array}{l}\text { Review \& Approval Desk,9612 } \\
\text { For DOE/OSTI }\end{array}$} \\
\hline
\end{tabular}

